\title{
Young, vulnerable and uncertain: Young workers' perceptions of work health and safety
}

\author{
L. Clarkson ${ }^{\mathrm{a}, *}$, V. Blewett ${ }^{\mathrm{b}}$, S. Rainbird ${ }^{\mathrm{b}}$, J.L. Paterson ${ }^{\mathrm{b}}$ and H. Etherton ${ }^{\mathrm{b}}$ \\ ${ }^{a}$ Australian College of Applied Psychology, Melbourne, VIC, Australia \\ ${ }^{\mathrm{b}}$ CQ University, Wayville, SA, Australia
}

Received 5 February 2015

Accepted 5 December 2017

\begin{abstract}
.
BACKGROUND: Young workers are at an increased risk of work place injury, and are less likely to report hazards or injuries, or apply for workers' compensation even though they are over-represented in workers' compensation statistics in comparison with their older peers.

OBJECTIVE: To identify young workers' perceptions of work health and safety (WHS), why and how they report (or do not report) hazards and injuries, and examine where they source WHS information. This paper reports on the first stage of a larger, mixed methods study on WHS and young workers in South Australia.

METHODS: A total of 226 young South Australian workers aged between 12 and 25 years completed an online survey. Data were analyzed using chi-squared analysis for categorical variables and $t$-tests where the dependent variable was continuous. RESULTS: Three quarters of young workers identified stress at work, not being trained to do the job, fatigue from work and lifting heavy things at work as WHS issues, although not necessarily as issues that they have personally experienced. Most young workers obtained information about WHS through their employer although a sizable proportion sourced this information from friends and social media. Young workers identified that they lacked confidence to report WHS issues. When they did report issues, many young workers reported these issues to their parents, despite identifying that their parents were often unable to help.

CONCLUSIONS: Our findings contribute to our understanding of young workers' perceptions of work health and safety. Although young workers could identify their concerns about particular health and safety related issues at work, they lacked the confidence to report their concerns and had limited information about where to go for help. The research suggests that there is a need to empower young people to report WHS concerns to their employer and provide structures and processes that encourage reporting.
\end{abstract}

Keywords: Injury reporting, training, online survey, vulnerable workers

\section{Introduction}

This paper reports on an online survey that was conducted as part of a larger, mixed-methods, commissioned research project aimed at developing a strategy for improving work health and safety among

\footnotetext{
*Address for correspondence: Larissa Clarkson, Australian College of Applied Psychology, Level 10, 123 Lonsdale St, Melbourne, VIC 3000, Australia. Tel.: +61 03 86130616; Fax: +6103 86130698; E-mail: larissa.clarkson@acap.edu.au.
}

young workers in South Australia [1]. The larger project included qualitative data collection comprised of focus groups, interviews, the use of social media, and a large group workshop (a Future Inquiry Workshop) with young workers and others with a stake in the area; including educators, parents, employers, unions and other community groups with an interest in youth. The survey was the first stage of the research and the findings informed the subsequent qualitative parts of the research. The findings of the survey 
also contributed to the conclusions, recommendations, and the final strategy for improving WHS for young workers in SA [2].

The survey aimed to identify young workers' views of work health and safety (WHS) in the South Australian population. The survey was designed to provide a broad-brush approach to identify young workers' views of key WHS issues and thus to enable the later stages of the research to target WHS issues that were relevant to young workers. Specifically, we aimed to investigate what young workers regarded as WHS issues; that is: hazards, near misses, incidents, and work-related injury or illness. We aimed to find out which issues were important to them and where they found information about WHS. We were also interested to ascertain who they report WHS concerns to, why they may choose to not report a WHS issue, and what happens when they do report a WHS issue. This paper reports only on the first stage of the research, quantitative findings from an online survey; the qualitative findings from the later stages of the research are reported elsewhere [3].

Young people (aged 12-25 years) comprise about $17 \%$ of the workforce in Australia and about $40 \%$ of the casual workforce. Furthermore, $92 \%$ of these are also students at secondary, Post-secondary (vocational), or tertiary levels [4]. Although the minimum legal age for employment in South Australia is 15 years of age, we know anecdotally that children under 15 can be found working in family businesses such as shops and farms. Thus the age group for this research was widened to include this younger group. Half of all young workers are employed under casual arrangements, primarily in the retail and hospitality industries; accounting for almost half of all young worker employment [5]. Although young workers comprise a minority of the workforce, workers' compensation data consistently reveal that they are at a disproportionate risk for work place injuries. In 20092010 , young workers under 25 years accounted for $20 \%$ of the work-related injuries experienced by all Australian workers. This is $18 \%$ higher than the rate for workers aged 25 years and older. Although young males are more likely to be injured at work, young females have a higher injury rate on a 'per hour' basis [5]. Added to this, it is known that young workers are less likely to report work-related injuries and illnesses, so the problem is likely to be greater than workers' compensation statistics reveal $[5,7]$.

There are well-documented factors contributing to the increased risk of work-related injuries for young workers. Precarious employment is one factor, although this appears to be gendered. Young casual female workers are twice as likely to be injured as their permanent counterparts [5]. However, there is no difference in the injury rates between casual and permanent young male employees when controlling for hours worked. Given that employment status does not appear to influence injury rates for young male workers, it is unlikely that the difference found in female workers is due to different training offered for permanent or casual staff, or differences in levels of experience. However, it is unclear how differences in industry-type may confound the interaction between gender and employment type. In Australia, the construction and mining industries (both male-dominated) have well-organised and legally mandated induction processes that make it difficult for new employees to be engaged without training. These provisions do not exist in the hospitality and retail industries, which are female-dominated.

Shift work; that is, work outside 09.00-17.00 hours, has a well-documented association with an increased risk of work-related injury [6]. Almost $25 \%$ of young workers engage in shift work as compared to $15 \%$ of older workers [5]. For many young workers, shift work takes place after their school or post-secondary education obligations; thus their paid employment may be equivalent to a second job. Regardless of age or gender, shift workers have an injury rate 35\% higher than non-shift workers [5]. Young shift workers are also at an increased risk compared to older shift workers, although this depends on gender and employment type (permanent or casual). A report [5] found that young female shift workers who worked part-time were more likely to be injured than older female and young male part-time shift workers. It is unclear whether these statistics include injuries sustained from traveling to and from work as journey accidents are non-compensable in some states and territories of Australia, including South Australia. Breslin and Smith [7] investigated whether young workers' increased risk was age-related or occupation-related by looking at injury rates among a large sample of young Canadian workers. When adjusting for occupation, they found that the type of employment young people tend to engage in plays a crucial role in their elevated risk of work place injury. This can be partially explained by the finding that young workers were more likely to be involved in occupations that require higher levels of perceived physical exertion.

In addition to their elevated risk, young workers are also less likely to report injuries or to apply 
for workers' compensation. Safe Work Australia [5] found that almost two-thirds of injured young workers did not apply for workers' compensation for their work-related injury, with the worker's perception that the injury was too minor to warrant a claim cited as the most common reason. This is supported by a Canadian study, where focus groups were conducted with young workers aged 16 to 18 years to identify why they did not report workplace injuries [8]. They found that young workers believed that injuries were part of the job as they happened frequently and were often not severe enough to warrant medical attention. Participants in that study also indicated that as young workers they felt unable to exert control in their workplace. Further, the response to reporting was related to gender; female workers reported that when they did report an injury, their claims were disregarded; while males were often unwilling to report an injury as they felt this would affect how their colleagues viewed them.

\section{Methods}

\subsection{Establishing the survey}

At the outset of the overall project we established a Project Steering Committee with social partners that included membership from the WHS regulator, workers' compensation authority, unions, business, industry associations, education and community groups concerned with young workers. This group provided us with input to the research design informed by their experience with young workers. They also helped facilitate access to research participants. The Project Steering Committee met regularly throughout the life of the project and was a valuable asset for the researchers and the project.

We also established a Young Worker Reference Group comprising six young people of diverse ages and backgrounds. This small group tested our ideas, provided us with insight into the use of social media, and helped us design the language we used in communication with young workers. They also helped us find young workers to user-test the survey and ultimately helped us to recruit the initial survey participants.

\subsection{Participants}

Participants were recruited using snowball sampling and via a strong online presence for the project, which included a webpage, a Twitter page, and a
Facebook page that led potential respondents to the survey's URL. We also paid for advertising through Facebook to attract respondents. Our social partners endorsed the survey and also encouraged young workers to participate by advertising the survey's URL on their websites. Participants were therefore self-selected, but needed to be aged between 12 and 25 years and live within South Australia. We provided an incentive to participate by offering those who completed the survey entry into a draw to win one of $15 \times \$ 20$ iTunes vouchers. There were 322 responses to the survey, of these 96 started the survey but did not complete enough questions to generate usable data. A total of 226 participants completed the survey and provided usable data. Approval for the research was granted by the CQUniversity Human Research Ethics Committee.

\subsection{Materials}

A 20-question online survey was prepared using Qualtrics (www.qualtrics.com). We sought input on the content of the survey from our social partners on the Project Steering Committee and we refined the survey following user-testing with the Young Worker Reference Group and others. User-testing allowed us to critically examine both the content of the survey and the survey's online logic before the survey went live. We user-tested to redundancy, that is, until no new information was furnished by users. The survey was live for 10 weeks between August and October 2013.

The survey was anonymous and asked basic demographic questions including age, gender, and work and study status. Participants were asked to select all of the items that they thought were related to WHS from a list of 22 that were featured across the literature on young workers. These items included psychosocial and bullying issues, precarious work, fatigue, the physical work environment, and training. Participants also had the option of including a different response in 'other'. Of the items selected as WHS issues, participants were then asked to select the top three WHS issues that were important to them. The next question asked participants about their sources for WHS information, with participants able to select from 13 options or write an 'other', different option. Participants could select all that applied. The next question asked participants how likely they would be to report a WHS concern for three potential concerns on a 10-point Likert scale. A total of six descriptors were included along the scale $(1=$ very unlikely to 
$10=$ very likely) and a central neutral point ('undecided') was included. If participants stated that they were at least somewhat unlikely to report a concern, then they were directed to answer why they would be unlikely to report. This was by a 9-point "select all that apply" section that included responses such as 'I haven't needed to report anything', 'I would get fired', 'They wouldn't take me seriously', and 'I don't know how to contact this person'. Participants were then asked to indicate how likely they would be to report a WHS concern to different individuals or groups. Again this was measured in a 10-point Likert scale from $1=$ very unlikely to $10=$ very likely. The next question asked whether participants had reported to different individuals and groups, including parents, business owner, supervisor, union, teacher, peer employees, or friends. If they indicated that they had not reported a WHS issue to those individuals and groups they were prompted about their reasons by a 9-alternative, forced-choice section including: "I haven't needed to report anything"; "They couldn't help me"; and "I don't know how to contact this person". If participants had indicated that they had reported an issue to particular groups and individuals, then they were prompted to say what happened when they reported. They were provided with five forced response options ranging from "I was fired" to "The problem was fixed". Participants were then asked to indicate how helpful particular groups or individuals were when WHS issues were reported. This was done by having participants rate each option out of five stars, where no stars indicated "not helpful" and five stars indicated "very helpful". No half star ratings could be given. The final section of the survey was an open-ended text box where participants could give any further information. These qualitative data were analyzed along with the qualitative data obtained through focus groups and interviews later in the research.

\subsection{Procedure}

Participants could access the survey at a time of their choosing using a link to the Qualtrics site. The link was made available through extensive marketing using social media, the website and e-mail through our social partners as described above. Participants were first asked to verify that they were over 18 or if not, that they had their parent's or guardian's approval to complete the survey. We eliminated computer automated responses by using a mandatory 'captcha' field. Participants could come back to the survey within a week if they chose not to complete it in a single sitting. After completing all of the questions, participants were thanked for their participation and were offered a chance to go in the draw to win an iTunes voucher. Their entry into the draw was directed to a unique gmail address established especially for the survey. Thus their competition entry was separated from their survey response so that their survey remained anonymous and confidential.

\subsection{Statistical analysis of the data}

Chi-squared analyses were used to investigate differences between males and females, and age groups on the questions about where participants source information, to whom they have reported a WHS concern, and to whom they would report a WHS concern, as well as age and gender effects on reasons for not reporting. A $t$-test was used to investigate whether the likelihood of reporting depended on the type of WHS concern. T-tests were also used to examine whether there were age or gender differences in participants' perceptions of how helpful people were when reporting WHS issues. An analysis of variance (ANOVA) was used to investigate the effects of age and gender of likelihood of reporting each type of WHS concern (hazard, injury, illness).

\section{Results}

\subsection{Sample demographics}

Of the 226 participants with usable data, the majority (63\%) were aged between 18 and 25 years, while $34 \%$ were between 15 and 17 years. A further 3\% were aged between 12 and 14 years. The majority of the sample were female (60\%). The majority (62\%) of the sample were combining work with study. For the 15-17 year group, $81 \%$ of the sample were combining study and work, compared to $53 \%$ of the 18-25 year group; the rest were either working only or studying only. Furthermore, $40 \%$ of the 18-25 year group said that they were working only (and not studying), compared with only $3 \%$ of the 15-17 year age group and none of the 12-14 age group. The majority of participants who study were studying at school $(43 \%)$, and $22 \%$ were at university. A few (10\%) were undertaking vocational training or taking a short course (3\%). Almost half (45\%) of participants stated that they worked casually, while $28 \%$ worked parttime. Almost half (45\%) of the participants worked 
in the retail sector and $17 \%$ worked in hospitality and accommodation. Smaller numbers worked in other industries. Given the small number of respondents in the 12 to 14 year age group, these were combined with the 15-17 year group, leaving two categories broadly defined as 'younger' and 'older' for the analyses.

Given the relatively small number of responses from a very large field, we do not assume that the responses are representative of all young workers in South Australia. While we expect that there was some sampling bias in the responses, that is, it is likely that youth with more interest in WHS would be more likely to respond to the survey, it is unlikely that sample bias could account for any of the findings below.

\subsection{WHS concerns}

Participants were asked to 'list all items that you think are WHS concerns'. The top 10 responses are displayed in Table 1. This table also indicates the most common responses to the question 'what are the most important WHS issues to you?' The percentage represents the proportion of the sample who listed that concern in their top 3. This table indicates that at least three quarters of respondents recognized stress at work, not being trained to do the job, fatigue from work and lifting heavy things at work as WHS concerns. However, only a quarter to a third indicated that these issues were important to them. Interestingly, while a quarter of respondents indicated that being bullied at work was a WHS issue that was important to them, only $69 \%$ of the sample identified bullying as a WHS issue.

Table 1

Top 10 responses to the questions 'list all items that you think are WHS concerns' and 'what are the most important WHS issues to you?'

\begin{tabular}{lcc}
\hline & $\begin{array}{c}\text { List all the } \\
\text { things that } \\
\text { are WHS } \\
\text { concerns }\end{array}$ & $\begin{array}{c}\text { What are the } \\
\text { most important } \\
\text { WHS issues } \\
\text { for you? }\end{array}$ \\
\hline Stress at work & $77 \%$ & $32 \%$ \\
Not being trained to do the job & $75 \%$ & $33 \%$ \\
Fatigue from work & $75 \%$ & $28 \%$ \\
Lifting heavy things at work & $75 \%$ & $27 \%$ \\
Illnesses caused by work & $72 \%$ & $15 \%$ \\
Bullying at work & $69 \%$ & $24 \%$ \\
Working with chemicals & $64 \%$ & $15 \%$ \\
Pressure to cut corners & $62 \%$ & $12 \%$ \\
Discrimination & $59 \%$ & $17 \%$ \\
Being yelled at & $58 \%$ & $9 \%$ \\
\hline
\end{tabular}

Those who worked but did not study, and those who combined work and study differed in their assessment of their top three WHS issues. Forty seven percent of respondents who were only working said that unpaid training was in their top three issues, compared with $30 \%$ of those who were working and studying $\left(\chi^{2}\right.$ $(1)=6.10, p=0.014)$. Those who were only working were more concerned about discrimination at work because of their youth (35\%), compared with those who were working and studying $\left(28 \% ; \chi^{2}(1)=8.23\right.$, $p=0.004)$.

\subsection{Source of WHS information}

Participants were asked about their sources of WHS information. They were able to tick all the options that applied to them. Training given at work or information provided by their employer was the most common source of information $(60 \%)$, while $48 \%$ said they found out about WHS through their supervisor. By 'employer' we refer to non-supervisory management at the organizational level, or the organization that employs young people. By 'supervisor' we refer to the young workers' direct line manager. Unions were also a source of information, with $46 \%$ sourcing WHS information through this channel. Nearly half of the sample (43\%) said they obtained information from their workmates, and 32\% said through social media. There was a significant relationship between age and source of WHS information. Older participants (18-25 y) were more likely to obtain information from training given at work than were younger participants $(12-17 \mathrm{y}), \chi^{2}$ $(1)=4.86, p=0.027$. Furthermore, older participants were more likely to cite their workmates as a source of WHS information than were younger participants $\chi^{2}(1)=5.01, p=0.025$. There were no other significant relationships between age and source of WHS information.

\subsection{Reporting behaviour}

Paired-samples $t$-tests revealed that participants were significantly more likely to report if someone gets injured at work $(M=8.34, S D=2.50)$ than if something at work might make someone ill $(M=7.29$, $S D=2.71 ; p<0.001)$. They were also more likely to report if something at work is unsafe $(M=7.72$, $S D=2.55 ; p<0.001)$. A $2 \times 2$ (gender $\times$ age) Analysis of Variance showed that older participants were more likely to say they would report something that had the capacity to make someone in the workplace 
ill $(M=7.57, S D=2.49)$ than younger participants $(M=6.55, S D=3.15 ; p=0.036)$. There were no significant effects of gender, nor was there an interaction between age and gender on likelihood to report something that would cause illness in the workplace. Furthermore, there were no significant effects of age, gender, or interactions for likelihood to report a physical hazard and likelihood to report an injury.

If participants indicated that they would be unlikely to report a WHS concern they were prompted to indicate why. Participants were classified as being unlikely to report a WHS concern if they scored five or below on a 10-point Likert scale that ranged from $1=$ very unlikely to $10=$ very likely. Participants were given eight response options, plus the opportunity to type another reason in 'other'. Participants could choose as many options as required. The percentage responses are represented in Fig. 1, which shows that for those young workers who do not report, this is primarily because they 'don't want to cause a problem' (64\%), and because they 'don't feel confident' $(61 \%)$. Furthermore, $63 \%$ of those aged 17 years and under were likely to not report because they felt 'too scared to report' compared with $27 \%$ of $18-25$ year olds $\left(\chi^{2}(1)=6.24, p=0.012\right)$. There were no other age-related effects.

Participants were asked to indicate how likely they are to talk about (report) a WHS issue to particular people including: parents, relatives, older friends, friends their own age, unions, supervisors, business owners, Health and Safety Representatives (HSR), co-workers, teachers, industry association, or SafeWork SA (the regulator). A HSR is a worker who is elected by their peers to act as their representative on health and safety matters in their workplace. The role is voluntary and has specific rights and powers that are described in WHS legislation. Participants chose a response from 1 to 10 with $1=$ very unlikely to report and $10=$ very likely. These responses are shown in Table 2. Participants were most likely to report to workmates and supervisors, and least likely to report to an industry association. Who participants were likely to talk to depended on age with younger respondents (12-17 y) more likely to talk to parents than their older counterparts $(18-25 \mathrm{y} ; p=0.014)$, while older participants were more likely to talk to a HSR than younger participants, $(p=0.008)$, and were more likely to talk to their workmates than younger participants, $(p=0.066)$; although this failed to reach significance. Furthermore, females were also more likely to talk to their parents than males $(p=0.012)$, and males were slightly more likely than females to talk to a friend their own age about their concerns $(p=0.061)$ although this failed to reach significance.

When asked who they had reported to, $79 \%$ of participants said that they had reported a WHS concern to workmates, while $65 \%$ said they had reported a concern to their parents. Sixty-four percent said they had reported a concern to their supervisor, and 63\% said that they had reported an issue to friends their own age. Fewer than $50 \%$ of participants had reported to other relatives, HSRs, teachers, unions, business owners or the regulator. Again, there were age-related differences with a significantly greater proportion

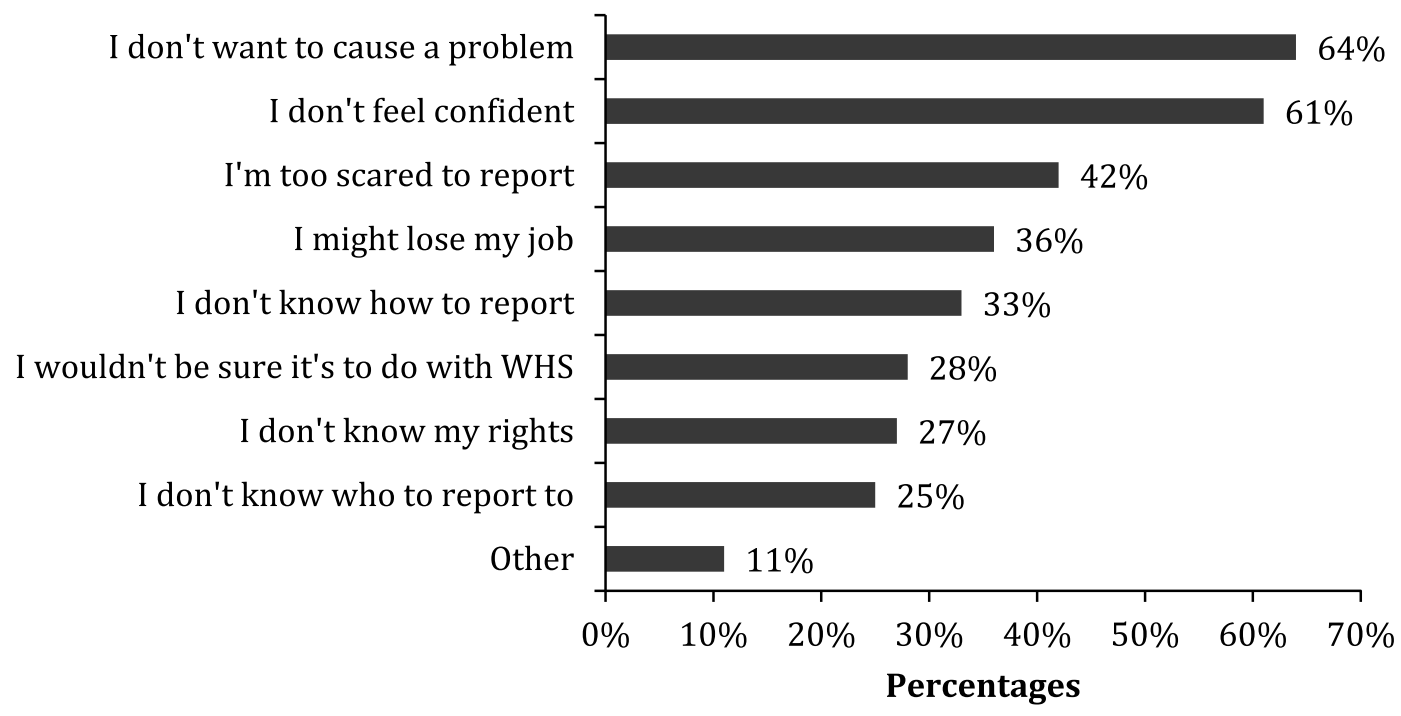

Fig. 1. Responses to 'You say you are unlikely to report a WHS concern. Why?' 
Table 2

Participants' responses about why they have not reported to particular individuals or groups. The percentage that had not reported to each is given in the second column

\begin{tabular}{|c|c|c|c|c|c|c|c|c|c|c|}
\hline & \multirow{2}{*}{$\begin{array}{l}\text { Have } \\
\text { not } \\
\text { reported }\end{array}$} & \multicolumn{9}{|c|}{ Why not? } \\
\hline & & $\begin{array}{l}\text { I haven't } \\
\text { needed to } \\
\text { report } \\
\text { anything }\end{array}$ & $\begin{array}{c}\text { This } \\
\text { person } \\
\text { was not } \\
\text { available } \\
\text { to me }\end{array}$ & $\begin{array}{l}\text { I would } \\
\text { get fired }\end{array}$ & $\begin{array}{c}\text { I would } \\
\text { be abused } \\
\text { or yelled } \\
\text { at }\end{array}$ & $\begin{array}{l}\text { I would be } \\
\text { ignored }\end{array}$ & $\begin{array}{c}\text { They } \\
\text { wouldn't } \\
\text { take me } \\
\text { seriously }\end{array}$ & $\begin{array}{l}\text { They } \\
\text { couldn't } \\
\text { help me }\end{array}$ & $\begin{array}{l}\text { Someone } \\
\text { else fixed } \\
\text { the problem } \\
\text { first }\end{array}$ & $\begin{array}{c}\text { I don't know } \\
\text { how to } \\
\text { contact } \\
\text { them }\end{array}$ \\
\hline Parent & $34 \%$ & $76 \%$ & $3 \%$ & $0 \%$ & $1 \%$ & $1 \%$ & $0 \%$ & $13 \%$ & $4 \%$ & $0 \%$ \\
\hline Other relative & $67 \%$ & $63 \%$ & $9 \%$ & $0 \%$ & $0 \%$ & $3 \%$ & $0 \%$ & $20 \%$ & $5 \%$ & $0 \%$ \\
\hline Workmate* & $20 \%$ & $80 \%$ & $0 \%$ & $0 \%$ & $0 \%$ & $8 \%$ & $5 \%$ & $3 \%$ & $5 \%$ & $0 \%$ \\
\hline WHS rep & $64 \%$ & $52 \%$ & $15 \%$ & $1 \%$ & $4 \%$ & $2 \%$ & $2 \%$ & $2 \%$ & $6 \%$ & $15 \%$ \\
\hline Friend my own age & $35 \%$ & $75 \%$ & $0 \%$ & $0 \%$ & $0 \%$ & $1 \%$ & $3 \%$ & $19 \%$ & $1 \%$ & $0 \%$ \\
\hline Older friend & $56 \%$ & $73 \%$ & $2 \%$ & $0 \%$ & $0 \%$ & $0 \%$ & $3 \%$ & $19 \%$ & $3 \%$ & $1 \%$ \\
\hline Teacher & $75 \%$ & $68 \%$ & $10 \%$ & $0 \%$ & $0 \%$ & $0 \%$ & $1 \%$ & $18 \%$ & $3 \%$ & $0 \%$ \\
\hline Union & $83 \%$ & $63 \%$ & $8 \%$ & $1 \%$ & $1 \%$ & $2 \%$ & $3 \%$ & $3 \%$ & $11 \%$ & $8 \%$ \\
\hline Supervisor & $35 \%$ & $62 \%$ & $3 \%$ & $1 \%$ & $7 \%$ & $9 \%$ & $12 \%$ & $1 \%$ & $3 \%$ & $1 \%$ \\
\hline Business owner & $55 \%$ & $59 \%$ & $6 \%$ & $2 \%$ & $4 \%$ & $5 \%$ & $14 \%$ & $2 \%$ & $5 \%$ & $4 \%$ \\
\hline SafeWork SA & $91 \%$ & $60 \%$ & $6 \%$ & $0 \%$ & $1 \%$ & $3 \%$ & $1 \%$ & $3 \%$ & $13 \%$ & $13 \%$ \\
\hline Business Association & $87 \%$ & $75 \%$ & $3 \%$ & $0 \%$ & $2 \%$ & $0 \%$ & $0 \%$ & $8 \%$ & $3 \%$ & $8 \%$ \\
\hline
\end{tabular}

*Note: some percentages do not sum to $100 \%$ for workmate due to rounding.

of older participants reporting to workmates $\left(\chi^{2}\right.$ $(1)=9.50, p=0.002)$, and to a HSR, $\left(\chi^{2}(1)=4.16\right.$, $p=0.041)$ than younger participants. Proportionally, older participants reported a WHS concern to their supervisor than younger participants $\left(\chi^{2}(1)=11.50\right.$, $p=0.001)$. There were also gender differences, with a significantly greater proportion of females reporting to a parent than males $\left(\chi^{2}(1)=9.84, p=0.002\right)$. Proportionally more males reported to a union than females $\left(\chi^{2}(1)=4.08, p=0.043\right)$; although, it must be noted that the proportion of the total sample that reported to unions was small $(17 \%)$.

If participants indicated that they had reported to a particular person or group they were asked to mark what had happened when they reported. Participants were given five forced response options, which included I was fired, I was abused or yelled at, I was ignored, I was listened to, the problem was fixed. If they said they had not reported to a particular person or group, they were asked why they haven't reported. They were given nine alternative forced choices including I haven't needed to report anything, I would get fired, they couldn't help me. These responses are reported in Table 2.

Participants were asked to indicate, on a scale of 1 to 5, how helpful certain people were when reporting WHS issues. Higher scores indicate that the person or group was more helpful. Responses are outlined in Fig. 2.

There was a relationship between the respondents' age and how helpful certain people were when given a report of WHS issues. Following the same trends as the results from previous variables, younger respondents found parents more helpful than older respondents did $(t(167)=2.02, p=0.045)$. Younger respondents also found business associations more helpful than older participants did $(t(151)=2.35$, $p=0.020)$. With regards to gender, males found HSRs at work $(t(155.07)=-2.84, p=0.005)$, SafeWork SA $(t(159)=-3.06, p=0.003)$ and business associations $(t(151)=-2.77, p=0.006)$ to be more helpful than females did.

\section{Discussion}

The aims of this study were to identify young workers' knowledge and experience of WHS; to identify who young workers talked to about WHS; and where they felt they could go if they needed to report an issue. Results indicate that the majority of respondents recognized stress at work, not being trained to do the job, fatigue from work, and lifting heavy things at work as WHS concerns. Whilst participants understood the importance of these concerns to their WHS, only one quarter to one third indicated that these issues were of interest to them. This may indicate that, for the majority of participant young workers, these WHS issues were well managed and were not of immediate concern to them, or that they had no personal experience of these concerns.

The results of this survey indicate that for young workers the psychosocial work environment is of concern, but is poorly understood by them as a WHS 


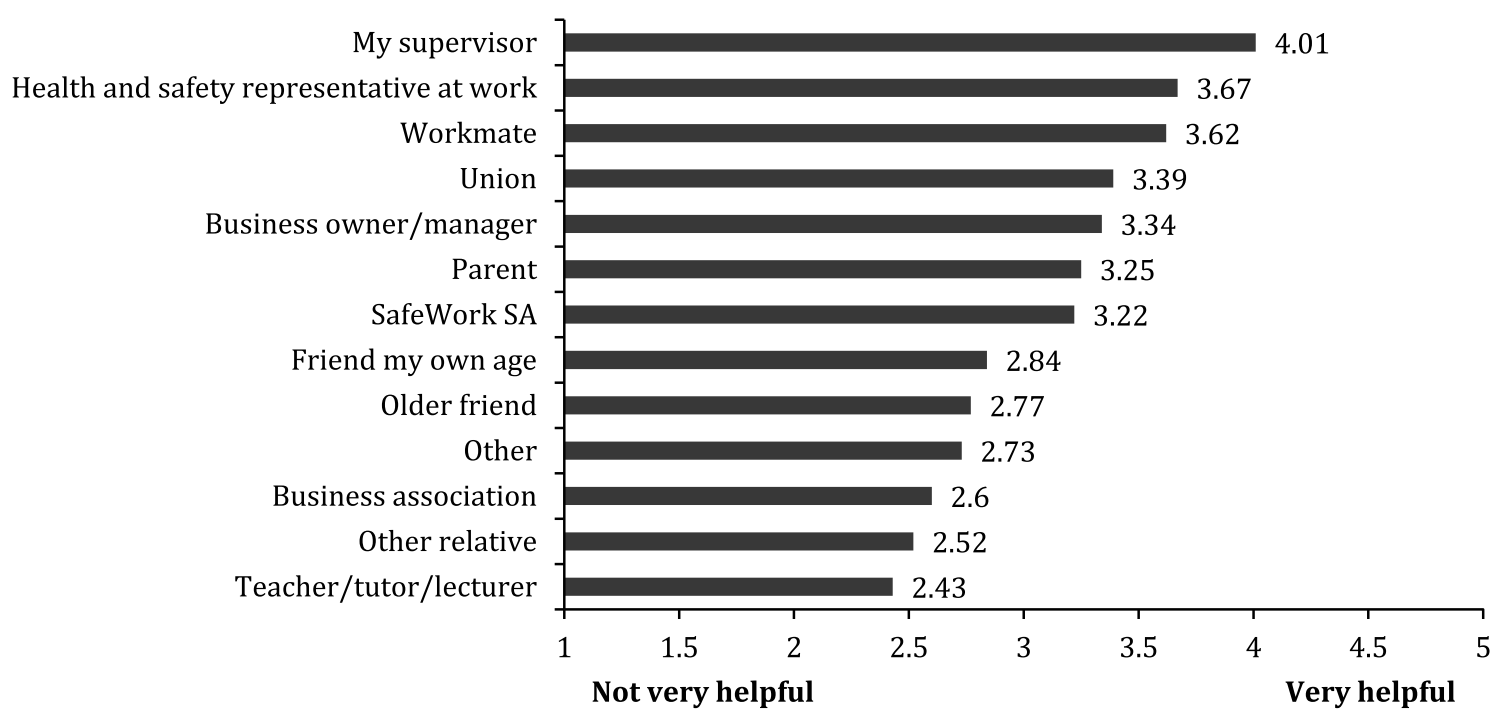

Fig. 2. Responses to "how helpful are the following people'.

issue. Just over half of the respondents recognized that being yelled at, at work (which is a form of bullying), was a WHS issue. One quarter of the respondents indicated that they had experienced bullying at work, but only $69 \%$ of respondents identified bullying as a WHS issue; there was a tension between their experience, knowledge and what was understood as a 'legitimate' WHS issue and not just 'part of the job'. This finding is in line with recent research from Brazil that showed young workers sometimes had little knowledge about work place harassment and were ill-equipped to deal with it [9]. This confirms the need for greater emphasis to be placed on the psychosocial work environment and associated WHS issues in the training of young people.

The differences between the WHS concerns of those who worked and did not study and those who both worked and studied indicate that a strategy for improving the WHS of young workers cannot be a 'one size fits all' approach, because different issues may be important for different types of workers. For instance, nearly half of respondents who were working and not studying said that unpaid training was in their top three issues compared with less than a third of those who were working and studying. Further, a quarter of those who were working only were also more concerned about bullying at work compared with only $10 \%$ of those who were working and studying. Similar discrepancies in this direction were found with those who listed a concern with discrimination at work because of their youth. Those who were balancing study and work were more likely to rate feeling pressured to 'do shifts', that is, to work more shifts, or shifts at times not necessarily convenient for them, than those who work only. We propose that young workers face difficulties when trying to strike a balance not only between work and life, but also between work and study; that is, their work/life balance is complicated by the additional demands of study. This is also clear in the literature. In a study of 15-24 year old workers who combined work with study, Patton and Smith [10] found that some young workers in their sample felt pressured to do shifts in their scheduled leave, although this was variable and most certainly not universal. Further research by Lewko et al. [11] found that some Canadian adolescents were working up to 20 hours a week and often worked after $11 \mathrm{pm}$, before going to school the next day. Evidently, balancing work and school and the need for restorative sleep would be difficult in this situation.

The issues regarding the selection of the timing and length of working hours, young worker's treatment at work, the respect shown to young workers, discrimination levelled at young workers because of their youth, and taking into consideration the balance between work life away from work and study, each contribute to the psychosocial working environment. While age discrimination is an equal employment matter, it also has WHS implications as it contributes to the psychosocial work environment, therefore we treated it as a WHS matter in this survey. It is unclear why the psychosocial issue of discrimination at work on the basis of their youth was more of a challenge 
for those only working as opposed to those who work and study. We postulate that those who are working while studying may have less commitment to their workplace that those who are only working. Work may be more important for young people who are only working because they are likely to have made career decisions or may be dependent on their work in order to live. Further research is needed to investigate this. However, previous research is clear about the implications of a negative psychosocial work environment. Frone [12] found that conflict with co-workers was predictive of depression, low selfesteem, and somatic symptoms in young workers. Furthermore, conflict with management or supervisors was predictive of low job satisfaction, intention to leave, and low organisational commitment.

While the majority of young workers indicated that they received WHS information from their workplace, almost a third indicated that they used social media as a source of WHS information. Rauscher and Myers [13] found that greater knowledge about WHS was associated with a higher prevalence of reported work place injury and attributed this finding to the amount of information respondents received from non-employer sources. This raises the issue of the veracity of information and confirms the need for formalised training of not only young workers, but also their workmates and line managers, so that the information passed on to young workers is accurate. While there were no gender differences in Rauscher and Myer's sample, Lewko et al. [11] found that females received more training than their male counterparts. Further research is needed to identify if a gender imbalance exists in South Australia.

Participants were more likely to report an injury rather than an illness. The significant effect of age on the likelihood to report an illness might reflect differences in experience and knowledge between the younger participants and the older participants that may make them less confident in identifying hazards that cause work-related illness. This indicates that training should focus on recognising and reporting hazards that could cause illness as well as injury, to increase the likelihood of reporting among these younger workers.

The reasons why young workers do not report incidents, near misses, or hazards at work was a cause for concern. The majority indicated that they do not report because they do not want to cause a problem and because they do not feel confident to do so. More than a third indicated that they were concerned that they would lose their job. Furthermore, those 17 years and under were also likely to not report because they felt too scared. This is clearly a concern that is preventing young workers from reporting and needs to be addressed. This differs from the findings of the national survey of young workers from Safe Work Australia [2], where it was found that young workers did not report because they did not feel that the injury warranted a workers' compensation claim. However, the focus of that investigation was to determine why young workers do not apply for workers' compensation rather than about reporting injuries and hazards to employers.

Participants were most likely to report to workmates and supervisors and least likely to report to a business association if they had concerns about an incident, near-miss, or hazard at work. To whom participants were likely to talk depended on age, with younger respondents more likely to talk to parents than their older counterparts. Older participants were more likely to talk to a HSR than younger participants, and were marginally more likely to talk to their workmates than younger participants. While it is unclear whether people did not report because they did not have an issue, and perhaps younger workers were less likely to have had a need to report, this may also reflect the lack of confidence the younger workers felt in negotiating the workforce on their own. This is supported by the finding that younger workers also felt too scared to report. This highlights the important role parents play in the work life of young workers, and the need for parents to be accepted as mediators on behalf of their children. It also indicates that information on reporting procedures needs to be given to young workers' parents as well as the young workers themselves, especially if that young worker is under 18 years. Such training or information dissemination could be mediated by schools. There are also gender differences with females more likely to report to a parent, and more likely to have previously reported to a parent. Employers need to be cognisant of these gender differences and ensure that avenues for parental mediation are open.

Interestingly, fewer than half of the participants reported their concerns to a HSR, although those who did felt that, in most cases, the problem was fixed. This is compared to parents and workmates to whom young workers felt comfortable reporting, but in the majority of cases these reports did not result in the problem being remedied. This indicates that the people young workers feel comfortable reporting to are not necessarily the people who have the capacity to improve or remedy the situation. Our findings showed 
that young people perceived supervisors and HSRs as the most helpful when reporting WHS concerns. The fact that young people were able to identify appropriate channels to report, but did not generally use these channels, is likely to be a function of two issues. The first is that sometimes the appropriate party is not readily available to the young worker. In fact $15 \%$ of young workers did not report to HSRs because they did not know how to reach them. This might be a function of the size of the employing organisation as very small enterprises (with fewer than 20 employees) are not required to have HSRs and many young people work in firms of this size. Secondly, the lack of confidence or fear in reporting to these people that has been identified in these data is important. This highlights the need to reiterate to young people the importance of reporting the issues to the appropriate channels, and for employers to ensure that the process of reporting issues is understood by young workers and that the response by the employer is encouraging. Primarily employers need to guarantee that young workers are able to report without negative ramifications [12].

Although this study provides an important first look at young workers' experience of the WHS systems in South Australia, it is not without limitations. The sample size is small, and given that there is an estimated 129,000 young workers in the state [15] and the recruitment methodology used, it is unclear how representative the sample is of the wider population of South Australian young workers. Further, almost $30 \%$ commenced the survey but did not complete it. Unfortunately, these participants did not provide any basic demographic information so it is unclear whether these differ from the sample included in the results. However, given that they had not completed any aspect of the survey, it is unlikely that their non-completion is related to any difficulties with the survey content.

\section{Conclusion}

The findings of this study add to a growing body of literature that aims to identify the reasons behind the over-representation of young workers in workers' compensation statistics, coupled with their underreporting of WHS concerns. This paper confirms that young workers in South Australia under-report WHS issues, and highlights concerns about their lack of confidence in reporting, especially for the youngest of the workers. The study also raises concerns around the psychosocial work environment of young workers, and reiterates the importance of ensuring that health, as well as safety, is an important aspect of WHS training [14]. When they did report issues, many young workers reported these issues to their parents, despite identifying that their parents were often unable to help remedy the work situation. Our findings highlight the need to empower young people to report WHS concerns to their employer but also indicate a continuing role for parents in the work place, especially for the youngest workers.

Whilst change should be encouraged at the organizational level, improvements are needed at the broader State legislative level as part of the work health and safety infrastructure provided by government agencies, unions, and employer associations. We identified the need for curriculum improvements at primary and secondary school, and in vocational and tertiary education to ensure that young workers are cognizant of their rights and obligations as workers in their chosen careers, as well as in their temporary, casual employment. We also find a continuing role for parents to facilitate workplace safety among their children of working age, especially for the youngest workers. As such, there is a role for government agencies and schools to provide information to parents of young workers to improve the quality of advice and support provided by parents to their working children. Further research is necessary to identify how these issues might be addressed and how change might be implemented to move toward healthier and safer workplaces for young workers.

\section{Acknowledgments}

This research was supported by Safe Work South Australia.

\section{Conflict of interest}

None to report.

\section{References}

[1] Blewett V, Rainbird S, Clarkson L, Paterson J, Etherton H. Developing the Youth Health and Safety Strategy for South Australia. Central Queensland University: Wayville, South Australia; 2013. Available from: http://library.safework. sa.gov.au/fullRecord.jsp?recnoListAttr=recnoList\& recno $=61585$ 
[2] Safe Work Australia [homepage on the internet]. Cited 2017 Jan 30. Available from: http://www.safeworkaustralia. gov.au/sites/swa/australian-strategy/case-studies/pages/saf ety-for-young-workers-in-sa.

[3] Paterson JL, Clarkson L, Rainbird S, Etherton H, Blewett, V. Occupational fatigue and other health and safety issues for young Australian workers: An exploratory mixed methods study. Ind Health. 2015;53(3):293-299.

[4] Australian Council of Trade Unions (ACTU). Independent Inquiry into Insecure Work in Australia, Lives on Hold: Unlocking the potential of Australia's workforce, 1-85. Retrieved from: http://www.actu.org.au/our-work/indepen dent-inquiry-into-insecure-work-in-australia/report

[5] Safe Work Australia. Work-related injuries experienced by young workers in Australia, 2009-10. 2013:1-64. Retrieved from: http://www.safeworkaustralia.gov.au/sites/swa/about/ publications/pages/work-related-injuries-experienced-byyoung-workers-in-australia-2009-10

[6] Folkard S, Tucker P. Shift work, safety and productivity. Occ Med. 2003;53:95-101.

[7] Breslin FC, Smith P. Age-related differences in work injuries: A multivariate, population-based study. Am J Ind Med. 2005;48(1):50-6.
[8] Breslin FC, Polzer J, MacEachen R, Morrongiello B, Shannon $\mathrm{H}$. Workplace injury or "part of the job"?: Towards a gendered understanding of injuries and complaints among young workers. Soc Sci Med. 2007;64:782-93.

[9] Turte SL, Correa ME, da Luz AA, Fischer FM. Harassment at work? Empowerment and autonomy as coping strategies of young workers. Work. 2012;41:5674-6.

[10] Patton W, Smith E. School students and part-time work: Workplace problems and challenges. Youth Studies Australia. 2009;28(3):21-31

[11] Lewko JH, Runyan CW, Tremblay CS, Staley JA, Volpe R. Workplace experiences of young workers in Ontario. Can J Public health. 2010;101(5):380-4.

[12] Frone MR. Interpersonal conflict at work and psychological outcomes: Testing a model among young workers. J Occup Health Psychol. 2000;5(2):246-55.

[13] Rauscher KJ, Myers DJ. Occupational health literacy and work-related injury among US adolescents. Int J Inj Contr Saf Promot. 2014;21(1):81-9.

[14] Chin P, DeLuca C, Poth C, Chadwick I, Hutchinson N, Munby H. Enabling youth to advocate for workplace safety, Safety Sci. 2010;48(5):570-79. 